\title{
Research on Implementation Process of Conditional Cash Transfer International Poverty Aid Project
}

\author{
Xiaoli Zhu \\ College of Economics and \\ Management \\ Yunnan Agricultural University \\ Kunming, China \\ lily7277@163.com
}

\author{
Lei Duan \\ Yunnan Exchange Center for \\ International Economy and \\ Technology \\ Kunming, China \\ 570983634@qq.com
}

\author{
Hao Yin* \\ International Business School \\ Yunnan University of Finance and \\ Economics \\ Kunming, China \\ yinhaoli@163.com
}

\begin{abstract}
Conditional cash transfers (CCT) international poverty aid project is an effective form of hematopoiesis poverty relief. An efficient project relies on thorough implementation process. The process is researched from the perspective of process management. Analyses are conducted on the origin, definition, features, and management of CCT project. Using lifecycle theory, the implementation process model is established. Planning stage, design stage, implementation stage and completion stage are distinguished in the model. So the using of the model can improve the effectiveness of CCT project.
\end{abstract}

Keywords: poverty aid, conditional cash transfers, process management

\section{INTRODUCTION}

The initial development aid and poverty alleviation had not any additional conditions. Political conditions connecting with aid project started from the 1990s. Since disadvantages of development assistance with additional political conditions are gradually revealed[7], Conditions were changed from political conditions into microscopic behavior conditions.

Conditional cash transfers (CCT) project is a poverty alleviation project with behavior conditions. It provides beneficiary families with cash directly. Whether a poor family is qualified for receiving the funds depends on whether the family meets the conditions set by the project. The Conditions usually are human capital investment in children (education, health and nutrition).

Management on the project of CCT is actually management on assistance effect, time and scale, so that CCT project may provide assistance product of the best quality to assistance receiver in reasonable time and with limited assistance funds.

\section{LITERATURE REVIEW}

\section{A. Aid Project and Performance}

There is no relationship between assistance and total growth [4]. Therefore, in most cases from micro aspects,

\footnotetext{
* Corresponding author
}

assistance project succeeds, but it does not have positive effects from the macro aspects.

Most projects aided by developed countries have completed the number objectives set during project approval in China. Execution performance of projects in agricultural, energy and hygiene sectors is especially excellent. Project success is highly dependent on good international cooperation [1]. Project life cycle management model plays an important role in project management.

With rapid scale expansion of international development assistance, the assistance system has been gradually improved. The assistance concept has changed from quantity to quality and from methods to results gradually. When faced with the challenges from the change, result-oriented management can be taken into consideration, so as to apply better management [8]. On the other hand, in order to achieve the objective, process management on assistance project is vital [2].

CCT assistance project has been proved to play positive effects in many aspects, and it has made especially great contributions to training ability of beneficiaries in poverty alleviation, there is clear evidence proving [3]. CCT project can indeed increase use of education and health care services, but final effects of its poverty alleviation ability training needs to be further validated. There are three reasons for project failure in meeting the expectations: imperfect project preliminary establishment, project implementation and project design [9]. Problems are concentrated in project preliminary establishment and project implementation while project design has less problems, which means that most problems can be avoided through continuous improvement during future implementation process.

\section{B. Management Models and Process of CCT Project}

Compared with traditional social assistance projects, CCT project pays more attention to setting of the targeted group, highlights demand orientation, and requires the beneficiaries and the implementer to undertake joint responsibilities [6].

Many stakeholders are involved in CCT project. In order to guarantee that beneficiaries meet the conditional requirements, project management raises extensive needs for the information management system. These information needs not only include how to identify targeted group, but also include setting of project entry and exit mechanism of the targeted group, as well 
as transfer conditions and size of the payment amount. CCT project puts forward strict requirements for how to determine the qualification of objects, approval procedures, mechanism of how to effectively provide transfer payment, and how to establish the monitoring and evaluation system.

Studies are carried out on the management model and management organization of CCT project. CCT project belongs to one of social protection projects, and most of them are managed by government social welfare or development departments on the unified basis, such as in Brazil, Columbia, Salvador, Jamaica, Mexico, Panama and Turkey [5].

CCT project mainly has two management models of vertical and horizontal management. The vertical management model is represented by Jamaica, Peru, Mexico and the Philippines. The horizontal management model is represented by Columbia and Brazil. Most countries that implement CCT projects have set up councils or joint committee with the government to be the main functional department or main government officers to be leaders, so as to undertake project management functions [6].

\section{FEATURES OF CCT AID PROJECT}

\section{A. Deep participation of Beneficiaries}

The conditions are undoubtedly the most different for CCT aid project. By emphasizing that subsidy can be received by beneficiaries only when they comply with relevant conditions formulated by the project and take their own action in return, the project aims to radically reduce the poverty risk of poor families in the future. Project of this kind highlights the joint responsibilities of the backer and beneficiaries. In addition, since the conditions set often require beneficiaries to use public service resources of education, medical and nutrition sectors, the project pays much attention to training beneficiaries' poverty reduction ability, namely, the assistance typically changing from blood-transfusion mode into hematopoiesis way. Viewed from assistance effects, the conditional aid can achieve the expected effects more easily than the unconditional aid.

\section{B. Beneficiary Selection Mechanism}

As a targeted social protection project, effective selection of target group can avoid omission or improper allocation of resources, and is the precondition to guarantee the project implementation effects. In accordance with experience of various countries that have implemented this kind of project, the targeting methods for beneficiary group of conditional cash transfer are mainly consisted of regional targeting and family group targeting. As for regional targeting, when considering selection of beneficiary group, specific region is taken as the basis, for example, families in the region where the dropout rate of children is relatively high will all be selected as beneficiaries. As for family group targeting, a series of quantitative criteria will be formulated firstly, such as family income level, gender or age of the beneficiary. The established criteria will be applied to determine the beneficiary group, with conditions available to be overlaid, for example, families that have school age children and whose annual income is lower than a certain standard are selected as beneficiaries. Most countries that use family group targeting mechanism have employed the method called "proxy means tests (PMT)", which estimates the per capita income or consumption through a series of variable factors observed. The variable factors include family composition, education background, ownership of durable assets, living conditions and availability of public services. This model has provided objective and unified evaluation criteria for family qualification for assistance. During actual practice, backers of many projects usually make use of the two methods at the same time.

\section{Reasonable and Transparent Payment Mechanism}

Designing the mechanism of subsidy amount will have direct effects on project implementation results, including the subsidy amount, subsidy receivers, subsidy payment levels and manner. It is vital to determine the proper amount of subsidy to reach the objectives of the CCT project within the limitation of funds. If the subsidy amount is excessively low, it may not be able to promote poor families to change their expenditure structure, and invest in the expected fields of the project. On the contrary, if the subsidy amount is excessively high, it will increase beneficiaries' income and effectively improve the poverty reduction greatly, but it may likely have adverse impacts on the labor market fluctuation, which is commonly known as assistance dependency.

CCT aid project will determine the benefit amount of each beneficiary family by comprehensively considering the factors like family poverty level, as well as the quantity, gender, age and education stage of direct beneficiaries. The subsidy amount is positively correlated to the grade and education level, and the subsidy amount will increase as the grade increase in Mexican "Opportunity Project".

During design of subsidy payment manner, the following issues shall be taken into account that the payment mechanism shall not only guarantee timely and correct distribution of subsidy funds to the beneficiaries but also proper allocation cost. The payment mechanism shall be practicable. The payment mechanism shall mainly include three aspects. Firstly, it shall reduce intermediate links of subsidy during management process. Secondly, project subsidies are distributed mainly through the existing infrastructures that have been generally covered in the rural regions, such as banking system or postal system, and beneficiaries can claim for subsidies directly in these infrastructures. Thirdly, reasonable frequency of subsidy distribution should be designed. The distribution cost will be excessive if subsidies are distributed frequently; but if the frequency is low, it is very easy to miss the period when poor families need support. As a result, project beneficiaries' confidence in continuing the project would be negatively affected, so to have adverse impact on the project effects. 


\section{ORGANIZATION AND MANAGEMENT OF CCT PROJECT}

\section{A. Organizational Structure}

CCT projects are a kind of social protection projects. Most of them are managed by government social welfare or development departments on the unified basis. Countries that implement CCT projects have set up councils or joint committee with the government to be the main functional department or main government officers to be leaders, so as to undertake project management functions. CCT project mainly has two management models of vertical and horizontal management. The vertical management model is represented by Jamaica, Peru, Mexico and the Philippines, where project plans are designed by the central or federal government for different regions to undertake the management responsibilities. The horizontal management model is represented by Columbia and Brazil, where after project entrustment agreements are signed by the local government and the central government, the local government is solely responsible for operation and management of the project.

\section{B. Monitoring and Evaluation}

The property of CCT project determines that high efficiency and success of the project cannot be achieved without strict and independent evaluation and monitoring. All CCT projects shall be monitored and evaluated, so as to confirm whether beneficiaries meet the conditions for subsidies. In addition, the conditions set are usually related to the use direction of funds after beneficiaries have received subsidies, which put forward more sustainable requirements for project monitoring and evaluation. Monitoring and evaluation mechanism has been established for most CCT projects to raise efficient use of the resources. With the help of information technologies, many countries that implement CCT projects have developed effective monitoring systems, including implementing "management information system (MIS)" to monitor the project. Brazil has taken the lead in developing an integrated management information system and a three-level monitoring system.

CCT project also attaches great emphasis on the function of evaluation. The evaluation authority is mainly consisted of third-party authority, and the evaluation report will be published on the website and open journals to receive supervision from the public. Mexico even have legislated specifically, stipulating that all CCT projects shall be evaluated.

\section{Management Cost}

Management cost varies in different stages of CCT project. Cost for targeting project beneficiary group at the beginning of the project usually takes up the biggest share in all costs. Project operation cost will decrease until identification of beneficiary targets has been completed. In the first few years, it took USD 1.34 of management cost to make transfer payment of 1 dollar to beneficiaries in Mexican "Opportunity Project". Three years later, it took only 5 cents of management cost to transfer 1 dollar. Therefore, it usually takes a relative long project lifecycle for CCT project to show its implementation effects.

The operation funds usually take up $5 \%$ of the total project budget for management cost in mature regions, which are represented by Mexico and Brazil. For example, the project management cost of Brazilian "Bolsa Familia Project" accounts for $4 \%$ of the project budget, while the project management cost of Colombia's "Familias en Acción Project" usually remains around $5 \%$ of the project budget. Compared with traditional aid projects, CCT projects have advantages in management cost.

\section{Process Model of CCT Aid PROJeCt}

\section{A. Components of Process}

Process consists of a series of activities. If business process is deemed as a whole in the view of system, the components of business process system are a series of activities it contains and each of those activities differs from one another. Elements that constitute the process activity include: activity subject, content, tool and processing object, etc.

1. Activity subject is the implementer of the activity or the decision maker who controls the activity. Usually, activity subject is the manager of project, such as the project personnel at all levels of the assistance project; however, for different project activity, the subject may be the beneficiaries of the assistance project.

2. Activity content means how to implement specific activities and what actions will be taken. The activity content will be different for different kinds of activities. In the CCT project, there are management and decision-making activities implemented by project managers to identify beneficiaries and medical service activities implemented by the beneficiaries to meet the set beneficiary conditions.

3. Activity tools are those living individuals or lifeless instruments used by activity subject to improve activity efficiency and effect. In modern project management, project information system which integrated with business process and management process becomes the efficient activity tool. For example, in the CCT project implemented in Brazil, the integrated management information system plays a key role in the whole process monitoring of the project.

4. Processing objects of an activity are resources. The object of CCT project is the management of aid funds. As the range of project type is continuously enlarging and complexity strengthening, some management activities are needed to ensure the smooth progress of project. The main processing object of management activity is information. Because of the particularity of CCT project, fund management activities and information exchange activities between project personnel at different levels become particularly important.

There are logical relations between activities. For example, there may be conditional relation between activities. Relations 
between activities in the process constitute the overall structure of project process. This structure has a function, i.e. the ability to exchange substance, energy and information with the surroundings.

\section{B. Objective and Level of Process}

Participants of CCT project usually include backers, project managers of government sector, project implementation institution, technical services provider and beneficiaries of the project.

core process usually includes setting beneficiaries in the project design stage, setting transfer conditions, time interval and payment amount, etc. The main process can be divided into primary processes according to the time sequence of the project lifecycle. Primary process can be divided into secondary processes and corresponding sub-processes according to management function after combining project work task breakdown and responsibilities of participants.

\section{Methods of Process Establishment of CCT ProjeCt}

\section{A. Lifecycle of CCT Aid Project}

CCT project process management system should cover the whole process of project planning management, implementation and exit. The whole process management system is constructed with overall process, process of project planning stage, process of project design stage, process of project implementation stage and process of project completion stage. Every process in every stage of the project includes a series of sub-processes.

CCT project is a one-off gradual process with starting point and ending point. The lifecycle of the project can be divided into several stages according to the properties and process that the project goes through. It is shown in Tab 1.

\section{Tab. 1 Activities of CCT Project Lifecycle}

\begin{tabular}{|c|c|c|c|}
\hline Planning & Design & Implementation & Completion \\
\hline $\begin{array}{l}\text { Assistance } \\
\text { demand analysis } \\
\text { Project } \\
\text { objective } \\
\text { Assistance } \\
\text { scope } \\
\text { Feasibility } \\
\text { analysis } \\
\text { Expected result }\end{array}$ & $\begin{array}{l}\text { Organizational } \\
\text { structure } \\
\text { establishment } \\
\text { Allocation of } \\
\text { responsibilities } \\
\text { Determination of } \\
\text { the beneficiaries } \\
\text { Determination of } \\
\text { transfer conditions } \\
\text { and time } \\
\text { Determination of } \\
\text { the payment } \\
\text { amount } \\
\text { Project initiation }\end{array}$ & $\begin{array}{l}\text { Implementation of } \\
\text { assistance services } \\
\text { Performance of } \\
\text { assistance conditions } \\
\text { Activity coordination } \\
\text { Completion of } \\
\text { transfer payment } \\
\text { Stage monitoring }\end{array}$ & $\begin{array}{l}\text { Overall evaluation } \\
\text { File consolidation } \\
\text { and filing } \\
\text { Exit mechanism }\end{array}$ \\
\hline
\end{tabular}

\section{B. Management Function Parallel Process System of CCT} Aid Project

According to the division by project management functions and combining the characteristics of CCT project, the whole process can be divided into four parallel process systems, i.e. organization management process, fund management process, project monitoring process, project evaluation process.

\section{Organization Management Process}

Organization management process is designed according to the workflow and information flow in the course of project implementation and includes professional workflow and management workflow of CCT project. Professional workflow of CCT project refers to the activity process constituted according to certain logical relationship by specific project activities decomposed according to project management work tasks. In this process, responsibilities of each participant will be determined based on the detailed operating procedures of CCT project, and implementation methods, implementation order, implementation time and coordination in the implementation process of related works will be arranged according to the project plan. Project management workflow mainly places emphasis on the establishment of project management organization, information communication process within the project, etc.

\section{Fund Management Process}

Fund management process is designed according to the flow regularity of the project funds. Fund flow is value motion in the working process of project. Being different from general aid projects, the aid mode of CCT project is that aid funds will be granted to beneficiaries in cash only if beneficiaries meet the set project conditions. A series of fund management processes are needed to standardize how funds are initiated by backer initially, go through certain processes and finally reach the hands of the beneficiaries safely and efficiently.

\section{Project Monitoring Process}

The purpose of project monitoring process is to carry out monitoring on the situation of project implementation and progress so that appropriate corrective actions can be taken in time when the project deviates from the plan. The monitoring and control on the project play a critical role in the success of the assistance project. The project monitoring is implemented based on the project objective and the project plan. By comparing the actual number of beneficiaries, amount of assistance funds and accomplished assistance effects of a certain period with the scheduled plan and the intended objective, whether the project progress is smooth will be analyzed. Once obvious deviation is found, corrective actions should be taken in time, which usually include: reviewing the integrity and rationality of the process, replanning the rest assistance plan and confirming whether the project plan needs to be adjusted according to the actual project situation.

\section{Project Evaluation Process}

Project evaluation process mainly carry out an overall measurement on the overall implementation situation of the project and is a systemic, objective and targeted evaluation on each project activity in the project completion stage. Evaluation is a management tool and organizational process guided by learning and action taking with the purpose of 
improving the planning, plan making and decision making of the current and future activities.

There are interrelation and correlative dependence between the parallel processes of the project, which constitutes the overall process of project implementation and management. An efficient and standard management process should be formulated to maintain a better dynamic management process, optimize management procedure and ensure the performance of management functions and smooth flow of all kinds of work flows within the system.

The project lifecycle stage process system and the management function parallel process system do not exist in isolation and there are mutual junction and interconnection between them. The process of the project planning stage usually corresponds to the organization management process which is reflected in each stage of the whole lifecycle of the project as it runs through the whole project process. The process of project implementation stage, in addition to the organization management process, also involves fund management process and project monitoring process. The process of the project completion stage mainly corresponds to the project evaluation process. Fig.1 shows the interrelation between the process system of each stage of the project lifecycle and the management function parallel process system.

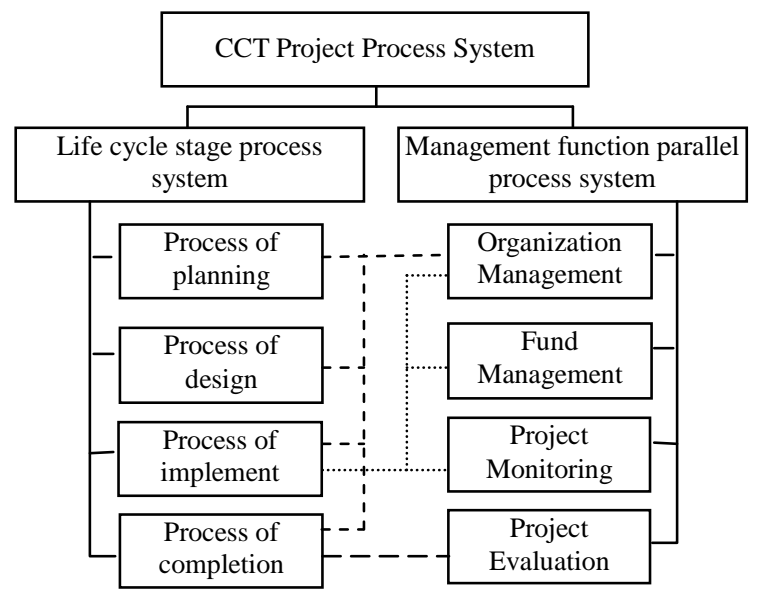

Fig. 1 CCT Project Process System Model

\section{StePs OF PROCESS EstaBlishMENT OF CCT PROJECT}

\section{A. Project Management Work Breakdown Structure}

The steps of project management work breakdown and establishment of corresponding processes are as follows:

1. Study and explore the management work of the assistance project, determine the principles of breakdown and divide according to management functions or project implementation order and other criterion;

2. Determine the management activity components of some management work based on the study and exploration on the management work of the assistance project, make each management procedure in the management work clear and preliminarily draw up the comprehensive process and corresponding sub-process of some management work;

3. Process implementation of each management function may has one or several basic sequence relations of different management activities and has non-uniqueness in the management business processing method and process, thus infeasible scheme or scheme obviously inferior to other schemes should be removed and a better scheme should be retained.

\section{B. Establishment of Responsibility Assignment Matrix of Management Process of CCT Project}

Responsibility assignment matrix is a method and tool to assign the decomposed work tasks to related departments or individuals and specifically shows their relations, responsibilities and positions in the organization. As responsibility assignment matrix is a chart composed of symbols and concise words, it is easy to make one and to understand its meanings. In addition, responsibility assignment matrix can clearly reflect the job responsibilities and mutual relations between departments or individuals of the project.

In the actual preparation process of responsibility assignment matrix of management process, to effectively assign responsibilities to specific departments or individuals, the organizational structure of the project should be fully considered which should be combined with the responsibility assignment matrix so as to provide convenience for the management responsibility division and the monitoring of related activities in the management process implementation.

\section{Establishment of Overall Process}

Full course is the most obvious characteristic of the overall process of the project which runs through the whole process of the project, according with the characteristic of the project lifecycle. Stage is another characteristic of the overall process of the project. To effectively control each link of the whole process of CCT project, the project lifecycle should be divided into several stages. Each stage has clear starting and ending rules so as to provide criteria for the decision making concerning connecting, developing and changing of each project stage.

the whole main Implementation process of the project is shown as Fig. 2.

Fig.2 shows that there is corresponding relationship between the overall implementation process of the project, the project lifecycle stage process system and management function parallel process system. As the project process management work itself is a complicated system, to realize the set project objective, a series of process activities should be carried out. Reasonable and efficient setting of those process activities and their intercoordination affects the smooth operation of the project. 


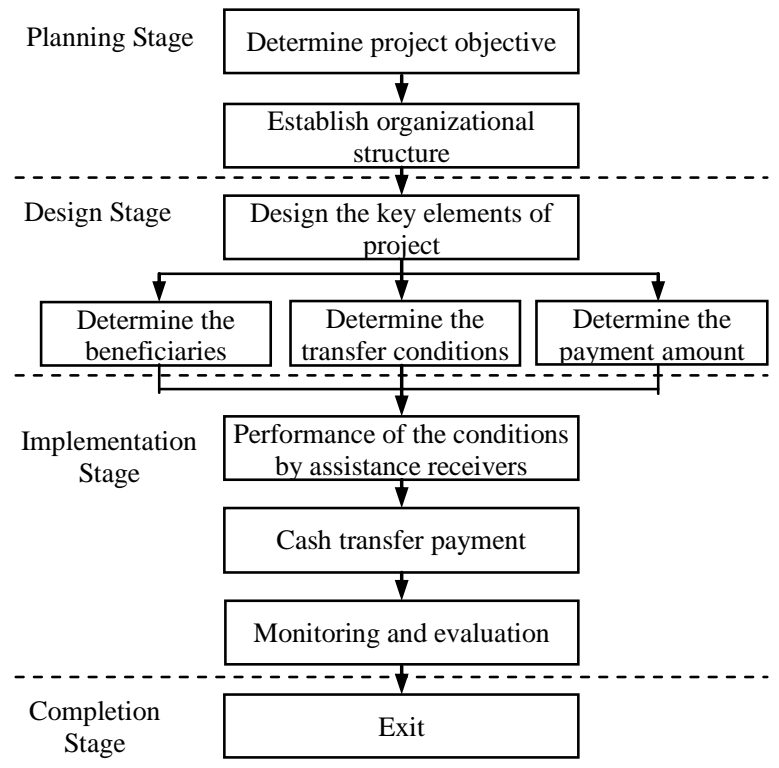

Fig. 2 Overall Implementation Process of CCT Project

Tab. 2 Table of CCT Project Process Management System

\begin{tabular}{|c|c|c|}
\hline $\begin{array}{l}\text { Lifecycle Stage } \\
\text { Process System }\end{array}$ & $\begin{array}{c}\text { Primary Process } \\
\text { Activities }\end{array}$ & $\begin{array}{c}\text { Secondary Process } \\
\text { Activities }\end{array}$ \\
\hline \multirow{3}{*}{ Planning Stage } & $\begin{array}{l}\text { 1. Definition of } \\
\text { project objective }\end{array}$ & $\begin{array}{l}\text { 1. 1Definition of project } \\
\text { objective }\end{array}$ \\
\hline & \multirow[b]{2}{*}{$\begin{array}{l}\text { 2. Establishment of } \\
\text { project organization }\end{array}$} & 2.1 Work task breakdown \\
\hline & & $\begin{array}{ll}2.2 & \text { Responsibility } \\
\text { assignment matrix }\end{array}$ \\
\hline \multirow{5}{*}{ Design Stage } & \multirow{3}{*}{$\begin{array}{l}\text { 3. Setup of selection } \\
\text { process of } \\
\text { beneficiaries }\end{array}$} & \begin{tabular}{|lr}
3.1 & Admittance \\
requirements & of \\
beneficiaries &
\end{tabular} \\
\hline & & $\begin{array}{|ll|}3.1 \text { Application process } \\
\text { for beneficiaries to join } \\
\text { the project }\end{array}$ \\
\hline & & \begin{tabular}{|lll}
3.3 & Exit process of \\
beneficiaries
\end{tabular} \\
\hline & \multirow{2}{*}{$\begin{array}{l}\text { 4. Setup of assistance } \\
\text { funds receiving } \\
\text { process }\end{array}$} & 4.1 Assistance conditions \\
\hline & & 4.2 Assistance standards \\
\hline \multirow{8}{*}{$\begin{array}{l}\text { Implementation } \\
\text { Stage }\end{array}$} & \multirow{3}{*}{$\begin{array}{l}\text { 5. Application and } \\
\text { granting process of } \\
\text { assistance funds }\end{array}$} & \begin{tabular}{|lrr}
5.1 & Application & process \\
for & subsidy & of \\
beneficiaries &
\end{tabular} \\
\hline & & 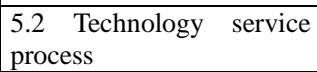 \\
\hline & & 5.3 Fund payment process \\
\hline & \multirow{3}{*}{$\begin{array}{l}\text { 6. Fund operation and } \\
\text { management process }\end{array}$} & $\begin{array}{l}6.1 \text { Application process } \\
\text { for project funds }\end{array}$ \\
\hline & & \begin{tabular}{|lll}
6.2 & Fund management \\
process
\end{tabular} \\
\hline & & $\begin{array}{l}\text { 6.3 Fund usage monitoring } \\
\text { process }\end{array}$ \\
\hline & $\begin{array}{l}\text { 7. Project monitoring } \\
\text { process }\end{array}$ & $\begin{array}{l}\text { 7.1 Project monitoring } \\
\text { process }\end{array}$ \\
\hline & $\begin{array}{l}\text { 8. Project supervision } \\
\text { process }\end{array}$ & $\begin{array}{l}\text { 8.1 Project supervision } \\
\text { process }\end{array}$ \\
\hline $\begin{array}{l}\text { Completion } \\
\text { Stage }\end{array}$ & $\begin{array}{l}\text { 9. Project evaluation } \\
\text { process }\end{array}$ & $\begin{array}{l}\text { 9.1 Project evaluation } \\
\text { process }\end{array}$ \\
\hline
\end{tabular}

The overall implementation process and respective secondary process activities of each process should be divided according to the stage process system and management function parallel process system. The corresponding relationship is showed in Tab.2.
Planning Stage include Defining the Project Objective and Establishing Project Organizational Structure.

Design Stage include Determination of Beneficiaries, Determination of Transfer Conditions and Arrangement of Transfer Time, Determination of Payment Amount

Implementation Stage include Standardized Service, Standardized Cash Payment, Management Information System

Completion Stage include monitoring, supervision and evaluation activities.

\section{CONCLUSION}

The implementation process of CCT poverty aid project is studied in this paper. Firstly, three features of CCT project were analyzed, these are deep participation of beneficiaries, beneficiary selection mechanism, reasonable and transparent payment mechanism. We studied the organization, management and process model of CCT Project. In sector of methods research, the concept of project lifecycle is introduced. Life cycle stage process system and management function parallel process system join together to form the CCT project process system. In the life cycle stage process system, there are four steps, they are planning, design, implement and completion process. In the management function parallel process system, there are four process. They are organization management, fund management, project monitoring, project evaluation.

\section{ACKNOWLEDGMENT}

We would like to express our sincere gratitude to H.E. Li Rongkang, for supporting us in investigation and collection data of the poverty aid project of United Nations International Children's Emergency Fund in China. We also want to thank the anonymous reviewers for their comments.

\section{REFERENCES}

[1] Chen Shuangfei. "Study on Developed Countries' ODA to China," East China Normal University, Shanghai(2007), pp.8-15.

[2] Lv Chaofeng, Zhu Dandan, Huang Meibo. "Tendency of International Development Assistance and Management System Reform of Chinese Assistance," Journal of International Economic Cooperation, 2014(11), pp.41-46.

[3] Liu Fugui. "Feasibility Study on CCT project of Children from Poor Rural Families," China Youth University of Political Studies, beijing(2012), pp.12-28.

[4] Finn Tarp. "Foreign Aid and Development," Routledge Press, London and New York(2000), pp.25-34.

[5] Tang Lixia, Zhao Lixia, Li Xiaoyun. "International Experience for CCT Poverty Relief Scheme," Guizhou Social Sciences.2012(8), pp.87-93.

[6] Xu Na. "Operation Management of CCT Project," China Society News. 2013(17), pp.3.

[7] Xuan Ye. "Study on "Conditional" and International Organization Assistance", Beijing Foreign Studies University, Beijing(2015), pp. $25-38$.

[8] Zhu Dandan. "The Impact, Challenges and Measures of International Assistance System and China's Foreign Assistance", International Economic Cooperation, 2013(3), pp.67-71.

[9] Zhang Haomiao."Indonesian Government's New Measures for Poverty Project , "Around Southeast Asia2014(9), pp.38-42. 